\title{
Subjectivity in ergonomics, a new start to the dialogue regarding the psychodynamics of work
}

\author{
Laerte ldal Sznelwar ${ }^{a *}$, François Hubault ${ }^{\mathrm{b}}$ \\ a*Universidade de São Paulo, São Paulo, SP, Brasil, laertesz@usp.br \\ bUniversité de Paris, Paris, França
}

\begin{abstract}
The emergence of subjectivity as a central issue of work pinpoints a dimension that is quite underexplored in ergonomics, even through the "activity ergonomic approach". Drawing on concepts related to an ergonomic approach concerned with subjectivity, not many answers exist. Part of this lack of answers can be solved through a dialogue with contiguous approaches proposed by other work sciences, such as ergology, the clinic of activity, or the clinic of work developed by the psychodynamics of work (PDW). The results of different studies provide evidence of the importance of subjectivity in work, especially if we take into account the emergence of mental health problems in different organizations. In this paper, we focus on the dialogue between ergonomics and PDW.
\end{abstract}

Keywords

Subjectivity. Ergonomics. Psychodynamics of work. Mental health.

\section{Introduction}

At the heart of questions raised by ergonomics centered on activity, is the evidence that there is always a discrepancy between the prescriptions of the task and the activity that is actually performed. The reality never corresponds to the perspective of those who have the power and the responsibility to plan and manage production. The economic objective of activity is to achieve the prescription - the task - in the real world. That for, workers have always to act differently of what was expected by managers and supervisors. Activity should be understood as the way someone engages himself in order to achieve goals.

But there are different goals to be considered, and this is for us, the reason to associate this founder observation to the following analysis: task and activity belong to two different ontologies. This is why it is absolutely inconceivable to deny the significance of task in the production process, whether it be to support planning and management actions, to which it acts as a model, or to support workers to whom it provides a benchmark to help the development of their activity. But, the emphasis should also be put on one fundamental difference with "classic" ergonomic approaches: subjectivy is always requested in activity, since anyone's work engages his body, his intelligence and his feelings.

Classic ergonomics focuses on reasons that limit workers' competences - physiological, cognitive - and this type of ergonomics is accustomed to dealing with the issue of either physiology or cognition or both. It took time before ergonomics committed to seeking through activity, not only to correct the insufficiencies of the task regarding the singularity of the real, but also to give way to one's own needs and expectations... attesting to the inalienability of autonomy in heteronymous activities. In such a perspective, an analysis of the activity is due to give evidence of this development standpoint and this emancipator perspective.

Since, we can part in two. First, ergonomics helped the psychopathology of work (PPW) to anchor the psychic activity onto the reality of work activity, but during this period ergonomics kept considering the subjectivity as an exclusive matter of PPW. Nowadays, ergonomics is facing the emergence of the 
theme of subjectivity related to workers' activity, and that gives rise to a new situation. Does it represent a nascent need to "take into account" issues related to the psychic activity, or is it simply a theoretical evolution in ergonomics? In our opinion, one cannot go without the other. In order to "take into account" these emerging issues, it is not enough to merely adopt ideas from disciplines where they have already been dealt with, we need to rethink the theory that allows to link these contributions to classic concepts in ergonomics. Thus, dialogue with psychopathology of work (PPW), then with psychodynamics of work (PDW) does not imply merging with this field, but considering how its arguments enlighten our concerns and challenge the itself development of ergonomics.

\section{At the beginning: initial dialogue}

Exchange of ideas with PDW, not only concerns concepts but action in such sensitive areas as work assessment, criteria applied for the design of tasks or those applied for productivity indicators which are finally used to evaluate workers' performance. Indeed, the question of the sense of work is what this encounter is focused on and, through it, emancipation as a goal of ergonomics.

The recent history of these two disciplines is punctuated by meetings where specific issues to each one have been debated, but also common issues. In the 80s, Dominique Dessors and Antoine Laville (Dessors \& Laville, 2009) ran a research with workers in a telephone company, where they demonstrated signs of deterioration of their health due to the invasion of work into private life, such as the contamination of speech and writing by automatisms acquired at work. They also pointed out the prevalence of digestive problems, the deterioration of sleep and perpetual fatigue suffered by these workers, mainly women. The authors gave also evidence of the changes in the character of these workers and stressed the consequences of these changes in the relationships they had with people around them. So far, this kind of health problem was not clearly associated with work even if they were discussed by Le Guillant and his colleagues some decenies before (Le Guillant, 2006). These "labor footprints" (Teiger, 2008) show that the experience of workers is indeed global and requires a reading and an interpretation which, for most part, go far beyond the usual ergonomic methodology.

It is important to state that in the 1980's those questions where discussed within the field known as psychopathology of work (PPW), which turned lately to be named psychodynamics of work when
Dejours (Dejours, 2008) introduced the question of pleasure at work as a field to be much considered. One can sum up the change this way: PPW was committed to understand the silent suffering of those who cannot invest themselves in their activity, when PDW was interested in understanding how the subjectivity and mental health can be improved through reflexive returns on the activity. Thus, in this second way, suffering is directly related to how subjective investment in the activity is attacked by the organization of work.

PPW pointed out a psychic issue which did not fit ergonomics: neither its conception of "activity", nor of the determinants of the task, nor of the organization, nor the concept of heteronomy - a concern that Dessors and Laville expressed on this occasion. Heteronomy specifies the condition of being under the domination of an outside authority, the subjection to an external law, rule, or authority, and thus to have to subordinate one's action to an end other than duty for its own sake. For ergonomics, il puts in clear that the activity is not only a response to a lack of the task in term of difference with the reality, but also - mainly ? - to the lack of the task in term of giving enough room to the achieving of the subjet -and collective- own goals. In the perspective set by these authors, the dialogue between ergonomics and psychopathology of work (PPW) appeared full of challenges that required ergonomics to evolve in its own ideational economy.

Other issues highlighted the fact that ergonomics and PPW were not working on the same theoretical fields and that their conditions of interpretation and their proposals do not belong to the same category. So it's clear that the perspective of Ergonomics and PPW working together was far from being obvious and that the similarity of some of their concepts further added to the ambiguity between their respective analyzes, For example, through the distinction between the real and the prescribed, Dessors and Laville emphasized that ergonomics and PPW do not perceive the same commitment of the subject, one basing its vision on physiology and cognitive psychology whilst the other basing it on psychoanalysis.

More important is that these issues relate to the status of the body and the concept of health in ergonomics and psychodynamics of work (from this point we'll comment the perspective of PDW). The aim for "tangible" transformation of work places ergonomics in the position of the search for replicable and transferable "objectives", at the time when PDW is preoccupied by the prospect of elucidating the psychosomatic economy engaged in the psychic relationship to work, and emphasizes 
the re-appropriation of the sense and the ability to act that subjects and collectives have (Dessors \& Laville, 2009).

On this basis, the perspective of continuity between ergonomics and PDW cannot be envisaged, but rather only a form of complementarily between them is conceivable. Ergonomic Activity Analysis would provide information into the domain of variability in work situations with, as the key issue, the design of tasks admitting regulation requirements in activity so as to reduce possible risks for health as well as for production during the "performance" of work. In PDW, issues would fall under the category of the sense, that is the question of finding out how, through procedures, work activity constitutes an experience which is attuned to the desires and history of workers. In this particular category, it is to feel being successful, doing one's work well and the possibility of establishing interesting intersubjective relationships at work which would be on the agenda.

In a follow-up to these discussions, it is interesting to bring forth some content of a dialogue between François Daniellou and Pascale Molinier in 2001.

For Daniellou (2001), the key weakness of PDW lies in its low processing capacity. Whatever its analytical strength may be, its capacity for action is rather weak and yet, in ergonomics, the achievement of effective change is fundamental. According to him, issues in PDW concern the setting up of defense and, therefore, focus on the suffering and the pleasure attributable to the dimensions of work. Thus, PDW would not show to be directly concerned by concrete changes in the reality of work and there is considerable uncertainty surrounding the consequences of its actions and the specific role of professionals in this field. Above all, he points out reasons in the ergonomic analysis which lead to questioning the fact that speech alone would suffice to account for the wealth in human activity. Thus, wrongly stressing the risk in ergonomics of the reification of people, the author, finally, comes to believe that the modeling of actions in PDW could support its ambition to influence decisions though, at the same time, the knowledge in this field could thus be put to test by the involvement.

Pascale Molinier (2001) readily reckons that whereas the PDW involvement always lies within clear and limited boundaries, it is not possible to determine the duration of the effects of an action in this area, no more than it is possible to determine how it operates. For her, the key issue is to consider that the appropriation or re-appropriation of the sense is likely to trigger transformative actions which the subjects will carry out without there being the possibility to regulate them beforehand.

With regard to the doubts that researchers or stakeholders have on the sense of what they do, she stresses the fact that uncertainty cannot be ruled out, for the very reason that PDW demands concern issues related to suffering, pleasure, mental health, the dynamics of identity, self accomplishment and that there is therefore, neither any fact to establish nor any particular goal to achieve: it is the dynamics of the groups, how it's possible to deliberate and develop working rules, that determines the wealth of the results. Molinier confirmed that the key difference between ergonomics and PDW is traceable to the fact that ergonomics is working in the perspective of objective transformations of work and thus has its expectations falling within the domain of actual changes in the conditions and the organization of work and, therefore, in the content of the task, whereas PDW would aim at modifying subjective relationship to work, thus aiming to raise, first, the specific autonomy and then the power to act together. She also questioned the possibilities of actual changes in working situations provided by an ergonomic intervention and the central issue related to the engagement of the workers in analysis and transformation of the work. The function of the dispositive that was set up is to place on the public scene what remains opaque and intimate in human activities, by creating conditions such that thought becomes addressed speech and that it unfolds with the promise of being able to undergo transformation into the power to act.

In ergonomics, methodology focuses on the "observables" which render possible the questioning and interpretation of what is being said or silenced by the workers according to what they memorize. It depends on what they have clear conscience of, within a process of clarification where workers are invited to speak for themselves. For the ergonomist, speech, at least initially, does not reveal everything which is going on, in fact, no more than it reveals all that is prevented from happening, in the way that the idea was proposed by Clot (2010) in a related field - "Clinic of Activity".

Contrary to ergonomics, PDW is centered on the issue of defensive blockades of thought in such a way that being able to reflect, think and speak constitutes a powerful means for transformation. In this perspective, the aim is to promote the development of an "authentic speech" resulting from a trend which consists in requiring everyone to speak in front of others and thus to overcome the unsaid of the group.

This point is crucial, considering that this possibility of emancipation through collective 
development of a different - i.e. "authentic" - speech should render it possible to move onto collective actions. However, it also implies admitting that the limits to overcome, as regards the power to act, are not found only in the subjective relationship to work, but also in the relationship of work organization to subjectivity. Therefore, it is necessary to look into the relationship between subjectivity and activity, from both ends. In order to do this, it is necessary to link this relationship to a third pole where sense and value of work are placed: economics.

\section{New scenarios and challenges for work}

Changes over the recent decades have provoked and, at the same time, express a real crisis of the relationship between work organization and subjectivity, a crisis of the means which correlates organization to the reality that subjectivity is confronted to in activity. Whereas this provides an interesting opportunity for a renewal of a dialogue between ergonomics and PDW, it is also a strategic opportunity to (re)think the relationship between sciences of work and economics (du Tertre, 2011).

Regarding the relationship between ergonomics and PDW, the context in which this encounter takes place has completely changed. The demands of the society and companies are no longer those which were supported in arguments held by Daniellou and Molinier, a fortiori, those held by Dessors and Laville. Widening the scope further, it's possible to state that the orientation of reciprocal influences has been reversed.

In the early days of the common history between these disciplines, some concepts embodied in ergonomics - such as the relationship between the real and the prescribed -, were incorporated by PDW, to the extent of even becoming a founding reference of its argumentation. As now is the time for ergonomics to look into the level of importance it attaches to subjectivity in the health-efficiency relationship, ergonomics must be questioned on whether/how PDW would become a source for inspiration.

Ergonomics is not opposed to the idea that individuals commit themselves to their work activities. Depending on the context, the content of the task and the sense which builds up within the working situation that they experience, it is accepted that their activities can foster self-fulfillment or, on the contrary, be a source of pathogenic suffering that can lead to a defensive withdrawal or the emergence of bodily and/or mental disorders, falling sick, even worse (Dejours, 2009b; Sznelwar, 2003). However, the issue of the commitment of the subject sets ground for the very reason that leads ergonomics to seek the understanding of the relationship of the subject to reality for those facts which fall under the heteronomy of work situations.

As far as we are concerned - that is with regard to the conception of ergonomics we seek to defend - the question of heteronomy is indeed fundamental. What is at stake in it is the understanding of how the relationship of subordination (work hierarchical relationship, employment and wage relationship) leaves room for a relative insubordination, activity bearing witness to, both and at the same time, loyalty to the intentions of the task and loyalty to the emancipation of the subject, based on the otherness of the reasons to act. With the rise of virtual and service-based economy this issue resurfaces around discussions on "what doing well means" where health issues, ethical and economic issues crisscross under extreme tension.

Forms of work organization favorite to the neoliberal industrial model, accentuate individualism and its pathogenic consequences for mental health. However "modern" this organization is labeled - such as for the Lean Production, for example -, the specific risk of the manipulation of subjectivity has been extensively pointed out in work sciences. The categorization of, on the one hand, objective worlds (enhancement of material and tangible dimensions, enhancement of value and regard for the formal framework of its production) and, on the other, subjective worlds (enhancement of intangible dimensions of value and the intersubjective conditions of its production) raises tensions between the prescribed and the real, increases the difficulty for the activity to re-bind what the organization perpetually $u n$-binds. And that renders more problematic, all in all, conditions for the assessment of performance and professionalization of management, conditions for managing health of the subjects and the collective dynamics of cooperation between them and conditions for the quality of service and economic efficiency of the organization.

At the heart of the dialogue between ergonomics and PDW there is, therefore, the fact that activity always engages subjectivity, which we understand as the ability to allow oneself to be influenced or affected by what happens around. This commitment reflects the sensitivity of the subject, it marks how what happens in the world also happens to the subject too and thus draws on his health, i.e. the resources that enables the subject to react. "Working" thus stands out as one of the most important sources for the development of subjectivity. 
If the subjectivating value of work cannot, thus, be separated from its economic value, there is, therefore, need for the renewal of the way ergonomics considers the tension between efficiency and health (Hubault, 2013). Which, actually, requires it to give room for subjectivity in a conception of activity whose stake is no longer reduced to performing the task in the real world - in which case suffering arises from the fact that activity finds no sufficiently effective solution to the resistance of reality - but also to find, within the task, means for the subject to consider him/herself as a subject - in which case suffering turn to be pathogenic from the fact that work does not provide enough satisfactory outcome to reflexive relationship with oneself.

At this point comes in an issue which is too extensive for the purpose of this article: activity can be approached either from the perspective of the resource that it provides to the subject to "ward off his folly" - pathogenic suffering indicating where this solution does not work/no more works - ; or from the perspective of the resource that it provides to the subject to achieve self-fulfillment, within his potential/expectations/projections - pathogenic suffering indicating where this solution does not work / no more works, when this subjective investment is attacked or prevented or even impeded.

There is nothing obvious here. The issue of subjectivity is not "natural" in classic ergonomics, which is, to a large extent, ergonomics with no subject. Focusing on the task, standard ergonomics is not really dealing with "work" (a term that it has come to avoid mentioning), since it is devoted to the way that human "functions" are committed to achieving the "objectives" of the organization. This prospect makes ergonomics homogeneous to approaches where "working" has no place, these very same approaches which inspire the engineering and management main stream that it aims to influence by joining it.

In fact, the distinction between ergonomics of task and ergonomics of activity lies in the meaning of subjectivity and its place in work. To be consistent ergonomics of activity needs to consider that the subjective issue of work is to provide the subject with the resource for his own goals. And, since this prospect comes into conflict with the other issue - economic - of activity in achieving the goals of the organization, we hence verify that this approach leads to revisiting the health model just as well as the performance model: the Health-Efficiency adjustment hinges, in fact, on the capacity of the activity to remain true to what "makes one feel good" (to oneself, to others, to the company, to the society, to the world). In other words, on the capacity of subjective projection to anchor onto strategic projection (attuning sense categories between them).

The various "agitations" - in the issue of health (psychosocial issues like the increase of mental problems related to work, like suicides and the increasing consumption of psychoactive drugs) just as in the economic domain (tensions on quality, conflicting relations with customers) - testify, therefore, a crisis of relationship to the reality. The overestimation of tangible dimensions compared to non-visible, non-tangible and non-materialized work dimensions is a health issue, because it is silent on the commitment of life itself which is, consequently, evicted from evaluation systems which are popular in companies. This dis-association of what happens in silence and in the invisibility of the "working" is the source of health problems, especially mental, experienced by a growing number of workers.

This is indeed the case, for example, for work conditions prevalent in services, especially in certain types of call centers where workers feel hindered in doing their work properly, which would require them to establish a service relationship based on genuine dialogue with the client, in order to attentively respond to their needs. However, they are unable to do so or they do it unsatisfactorily because their ability to act is impeded by the organization of work which extensively manipulates their subjectivity by imposing rules that contradict the very attention it claims to support, by demanding a commitment that must at the same time, leave aside any feelings and act in total silence among the many reasons which promote the emergence of different kinds of pathogenic suffering (Sznelwar, 2003).

Our research-contributions on this subject reassure us of the interest there is to understand the relationship between conditions of work activity and the evolution of subjectivity and, therefore, the interest for ergonomics and PDW to exchange their views even further.

\section{Meaning of work}

It is indeed a key responsibility for organizations to provide tasks that have sense. "Having sense" means making it possible that, within the constraints of the task, workers should find sufficient flexibility to build up relationships with the hierarchy based on the usefulness of their work, relationships with colleagues based on cooperation and the sense of compliance with rules of their profession. In each situation, "having sense" refers to the question of "relevance", that is the possibility of making compatible, on the one hand, the standard and 
the specific and, on the other, the global and the local. For service activities, there is, in addition, the issue of the relationship with the customer based on the concern for the common good. In this case, relevance also concerns the possibility to manage tensions between two heterogeneous axes, on the one side the issue of the industrialization of service in which the logic of "service provision" drives to a reification of relations and, therefore, of workers and customers and, on the other side, the issue of service customization or the logic of "service relationship", intersubjective, which can be considered only through the view point of honoring life, the development of culture and of the "living together" (Dejours, 2009a).

In this context, the emergence of work-related psychological disorders rings a bell for ergonomics, as a call to order. They call upon the re-examination of what "activity" means. It is now much clearer than ever before that activity is not an observable and, all in all, one should talk of the analysis of work through activity rather than the analysis of activity. Activity is a concept, thus an operator for interpretation and understanding; it is not substantial reality.

The reason why we are taking the risk to reconsider the definition of activity is because it is necessary to regard it as an expression of the commitment of the subject and therefore his identity and desires. Whereas task is related to the goals to be attained and the means available to achieve them and, therefore, contributes to a "use of oneself by others", activity, on the other hand, involves the "use of oneself by oneself" (Schwartz, 2000), the commitment of the body and the ethics of doing (Dejours, 2009a), and therefore calls for an existential conception of the activity (Cazamian et al., 1996) where sense concerns both economic and subjective reasons, and indeed how these reasons concord (Hubault \& du Tertre, 2008).

\section{Promoting the dialogue}

Among the topics currently under discussion and which are at the heart of the dialogue with PDW the following are worth focusing upon in this paper:

1. First, the issue of assessment, a key responsibility in management, in which the main problem concerns disagreements about relationship to reality, which are the source of pathogenic suffering in service activities when these disagreements are not "worked out". The invisibility of the reality of work just as well as the invisibility of the commitment of subjectivity that confronts it, pose a serious problem to the evaluation and require designing systems which do not limit, beforehand, the assessment to the measurement.
(Dejours, 2003, 2011; Hubault \& du Tertre, 2008; Sznelwar et al., 2008; Uchida et al., 2011).

2. Secondly, the issue of autonomy. In most cases where workers are hindered in their attempt to work towards a resolution of clients' problems, with whom they are in direct contact, lead them to impasses which quickly become risks to their mental health. Especially when they can only manage to get away with through lies (Sznelwar \& Uchida, 2011; Rolo, 2011), which are more or less deliberate, whose deleterious effects are very difficult to contain and, potentially constitute a real challenge for the management of the organization. It is also necessary to clarify the ambiguity regarding the use of the concept of autonomy which is currently popular. Companies show a strong inclination to the concept of autonomy as a lever for demanding more and more from workers. Faced with this manipulation of subjectivity which is developing through new management practices, it is really essential to be able to include the commitment of subjectivity in the context of individual and collective emancipation through work which, we believe, requires profound tallying between ergonomics and PDW.

3. Then comes the issue of cooperation (Dejours, 2009a), which includes some of the previous issues, but also goes beyond them. Assessment calls for vertical cooperation. Whereas relation to the customer or with other teams or services within the company calls for the transverse cooperation. Collective work calls for the dynamics of horizontal cooperation where the nature and the quality of interaction between peers and between colleagues are regulated. The balance between these cooperation areas is fragile. For example, individual assessment often ruins the prospects of horizontal cooperation and yet, weakens the very foundation of collective performance; the degradation of horizontal cooperation worsens the difficulties of learning with colleagues, of exchanging ropes of the trade in order to resolve certain issues such that, little by little, competition replaces cooperation and, in the end, loneliness, isolation and its lineup of pathogens supplant cooperativeness.

4. Lastly, regarding action, it is essential to develop a listening strategy that combines professionalization of "educated" listening and legitimization of speech. In fact it is essential to encourage more and more labor speeches: public speech (e.g. epidemiological studies), individual speech (interviews), collective speech (particularly public debate on work expressions) and even more, to ensure their attunement in discussion places, in so doing, promote the semiotization of activity. However, it is equally essential to understand that 
"spontaneous" speech relieves the complaint rather than the suffering, and that "defenses" come forth to silence and bury what we should learn to listen to beyond "what is said".

This brings us back to the question of considering, not only organizational structures for listening, but also ones that allow for the development of deontic activities (Dejours, 2009a). Undoubtedly, such systems for discussing on work constitute a coherent spirit with the objective of emancipating subjects and collectives, based on relationships which built within the work collective and in setting up activities based on production demands that have sense. It is obvious that this also requires repositioning management onto the understanding of the "human resource" that is focused on the sustainable development of the power to act.

5. Further, does all this not underline the interest to (re?)-involve politics in ergonomic issues, as elsewhere in work sciences? This means to dig the bond between activity and emancipation.

According to us, ergonomics indeed, is concerned with the way in which the world raising from the activity resounds with the world wished-awaited by the culture, the society - that is the political value of the activity. Since, grounded on this basis, the centrality of work emphasizes this added statement: the activity of work is not any activity. For at least three reasons which makes a difference:

- the judgment on its contribution to the common good -i.e. the specific utility of the work activity-, and the stake of the judgement of the peers on the manner of carrying it out;

- the mode of domination/subordination experienced in this activity, and the mode of subversion/ insubordination which is opposed through this activity;

- the mode of remuneration/affiliation/counterpart which assesses the "performance" (i.e. the success of the activity).

The difference introduced by work is directly indexed in the room given to subjectivity into (the analysis of) the activity: work does not fit in the same development prospect as the use, neither from the point of view of the company, nor from the point of view of the subject, nor from the point of view of the society. Thus, the status of subjectivity in (the analysis of) the activity is clearly echoing to the question of the singularity of the activity of work, and, therefore, the centrality of work.

\section{Conclusion}

To conclude, between ergonomics and psychodynamics of work, exchange of ideas started a long time ago. However, whilst ergonomics has, in particular, sustained psychodynamic during its founding stages, today PDW re-launches ergonomics right into its fundamental ambitions by inviting it to go beyond mere prevention of risks and turn to health development and consider, in the same trend, health as the ability to act whose psychic dimension cannot be ignored or even, at the end, separated from all others. It would be important to advance even further the concept of activity, since it would no longer mean defining it in a quasi computational prospect which adds dimensions - physiological, cognitive, or socio-historical, cultural, psychosocial - onto each other, but to place it in more wider and profound prospect of the commitment of the body, of which the concept of subjectivity is precisely the issue.

In this article we therefore advocate the incorporation of knowledge from the psychodynamics of work into the debate on the ergonomics of activity. However, PDW is not the only area where the issue of subjectivity in the workplace is on stage. It is also the case, for example, in the clinic of activity, through another epistemological affiliate. It should equally be pointed out that PDW itself borrows ideas from other areas of expertise, for the same reasons which may justify that ergonomics gets interested in them too, even if the related authors do not considered work as a central issue. This is the case, for example, in the philosophy of the principles of Maine de Biran, for the clarification it provides on the anchorage of the development of thought in the experience of challenges faced during childhood or, still, in the concept of "body-propriation" by Michel Henry, a very powerful concept for the understanding of how the development of intelligence is linked to the body, that is to say the experience of the flesh. (Henry, 2001; Dejours, 2009a)

However, in the discussion with PDW, we must distinguish the field of concepts from that of actual action. Talking about concepts, one is confronted with the vision of the human being to be adopted. PDW refers to a human being to whom acknowledgment must be a way towards emancipation. Saying this is stressing that working is involved in the development of civilization and culture and, at the same time, that it must allow the subject to place him in his society and its culture. For PDW this is the reason for distinguishing activity from action, action being placed at the political and moral level, which activity does not/cannot achieve. But, by so stating, PDW suggests an accepting the type of activity which is more restricted than that we seek to develop by revisiting health-subjectivity-activity 
relationship, in ergonomics. It is perhaps through the way of considering the difference between praxis and poïesis as distinguishing between, either two types of activity or, rather, between two dimensions of activity that it is finally possible to heighten the degree and mode of tallying between PDW and Ergonomics.

In regard to action, there is also need to debate between these two fields. While ergonomics is more linked to concrete changes in working situation, PDW propose a reappropriation in terms of enhancing the capacity to act in a collective way. Certainly this proposal is not only correlated to "give a room" to the speech of workersbut a device of collective reflection about what working means and its relation to the constraints related to the tasks molded by organizational and strategic choices. It means that it is important not only to reaffirm the capacity of reflexion but to achieve confidence not only in a homogenic group of workers but to enhance the possibility to influence choices in the organization. It should be considered as something that could be adopted by an ergonomic approach, since the involvement of workers that actually face the work situation is pleded by many different authors in the field. The matter is to understand that workers have different thinks to adress, not only those related to what they do and how they act in terms of a instrumental rational but also relating to axiologic values and to subjectivity.

And this is the very stake of improving a strategy of listening through ergonomic intervention on working out the disagreements on quality (what does quality means ?), deliberating about the means to promote for improving autonomy, cooperation, assessing the real stakes which are faced in the work activity which strategy that must come to the very heart of activity analysis.

\section{References}

Cazamian, P., Hubault, F., \& Noulin, M. (1996). Traité d'ergonomie. Toulouse: Octarès.

Clot, Y. (2010). Le travail à cœur: pour en finir avec les risques psychociaux. Paris: La découverte.

Daniellou, F. (2001). L'action en psychodynamique du travail: interrogations d'un ergonome. Travailler, (7), 119-130.

Dejours, C. (2003). L'évaluation du travail à l'épreuve du réel. Paris: INRA Editions. http://dx.doi.org/10.3917/quae. dejou.2003.01

Dejours, C. (2008). Travail, usure mentale (pp. 215-259). Paris: Bayard.

Dejours, C. (2009a). Le travail vivant: travail et émancipation (Tome 1, pp. 25-44). Paris: Payot.

Dejours, C. (2009b). Le travail vivant:travail et émancipation (Tome ll, pp. 73-112). Paris: Payot.
Dejours, C. (2011). La psychodynamique du travail face à l'évaluation: de la critique à la proposition. Travailler, (25), 15-28. http://dx.doi.org/10.3917/trav.025.0015

Dessors, D., \& Laville, A. (2009). La signification du discours ouvrier: ergonomie et psychopathologie du travail. Incompatibilité ou complémentarité. In D. Dessors (Ed.), De l'ergonomie a la psychodynamique du travail (pp. 93121). Paris: Clinique du Travail.

Du Tertre, C. (2011). Economie du temps et risques psychosociaux: une approche économique semifonctionnaliste, semi-institutionaliste. In F. Hubault (Ed.), Risques psychosociaux: quelle réalité, quels enjeux pour le travail? (pp. 179-186). Toulouse: Octarès.

Henry, M. (2011). Philosophie et phénoménologie du corps (6th ed., pp. 253-308). Paris: PUF. http://dx.doi. org/10.3917/puf.henry.2011.01

Hubault, F., \& Du Tertre, C. (2008). Le travail d'évaluation, In F. Hubault (Ed.), Evaluation du travail, travail d'évaluation (pp. 95-114). Toulouse: Octarès.

Hubault, F. (2013). (re)Penser l'ergonomie à partir des questions qu'on lui pose. In F. Hubault (Ed.), Persistances et évolutions: les nouveaux contours de l'ergonomie (pp. 3-14). Toulouse: Octarès.

Le Guillant, L. (2006). Le drame humain du travail. Toulouse: Éditions Érès.

Molinier, P. (2001). Souffrance et théorie de l'action. Travailler, (7), 131-146.

Rolo, D. (2011). Novas perspectivas sobre o sofrimento ético no trabalho: o caso da mentira como prescrição. In L. 1 . Sznelwar (Ed.), Saúde dos bancarios (pp. 83-103). São Paulo: Publisher Brasil.

Schwartz, Y. (2000). Le paradigme ergologique, et le métier de philosophe. Toulouse: Octarès.

Sznelwar, L. 1. (2003). Working and impediment: the causes and consequences of inadequate task content and work organisation. In XVth Triennal Congress of the International Ergonomics Association and 7th Joint Conference of Ergonomics Society of Korea, Seul. Seul: Japan Ergonomics Society, Ergonomics in the Digital Age.

Sznelwar L. 1., Uchida S., \& Mascia F. (2008). De l'impossible evaluation de ce qui n'a pas de limite et des conséquences pour ceux qui ont quand même à y faire face. In F. Hubault (Ed.), Évaluation du travail, travail d'évaluation (pp. 41-64). Toulouse: Octarès.

Sznelwar, L. 1., \& Uchida, S. (2011). 0 trabalho bancário e a distorção comuinicacional: quando a mentira é parte da tarefa. In L. 1. Sznelwar (Ed.), Saúde dos bancários. São Paulo: Publisher Brasil, p. 105-124

Teiger, C. (2008). Entrevue guidée avec David H. et Cloutier E. Pistes, 10(1). Les défricheurs de pistes. Retrieved from http://www-pistes-uquam.ca/v10n1/articles/v10n1a4. htm

Uchida, S., Sznelwar, L. 1., \& Lancman, S. (2011). Aspects épistémologiques et méthodologiques de la psychodynamique du travail. Travailler, (25), 29-44. http://dx.doi.org/10.3917/trav.025.0029 